\title{
Prognostic value of extravascular lung water assessed with lung ultrasound score by chest sonography in patients with acute respiratory distress syndrome
}

\author{
Zhen Zhao ${ }^{1}$, Li Jiang ${ }^{1 *}$, Xiuming Xi', Qi Jiang ${ }^{1}$, Bo Zhu', Meiping Wang ${ }^{1}$, Jin Xing ${ }^{2}$ and Dan Zhang ${ }^{2}$
}

\begin{abstract}
Background: The prognostic value of extravascular lung water indices (EVLWI) has been widely investigated, which is determined by lung ultrasound B-lines. However, the clinical value of lung ultrasound B-lines for determining prognosis/intensive care unit (ICU) outcomes in patients with acute respiratory distress syndrome (ARDS) has been rarely reported.
\end{abstract}

Methods: Twenty-one ARDS patients admitted to the ICU of Fu Xing Hospital underwent both lung ultrasonography and pulse index continuous cardiac output (PiCCO) monitoring on the first, second, and third days after diagnosis. The correlation between lung ultrasound score (LUS) and EVLWI measured by the PiCCO system was investigated. The prognostic clinical value of lung ultrasonography in ARDS patients was explored. Chest ultrasound was performed using the 12 regions method. The comprehensive score of lung ultrasound was determined according to the level of lung aeration.

Results: With ICU mortality as the end point, 21 patients were divided into a survivor group (8 patients, $39.1 \%$ ) and a non-survivor group (13 patients, $61.9 \%$ ). Significant positive linear correlations were found between LUS and EVLWI, including predicted body weight $\left(r^{2}=0.906\right)$, sequential organ failure assessment score $\left(r^{2}=0.815\right)$, lung injury score $\left(r^{2}=0.361\right)$, and $\mathrm{PaO}_{2} / \mathrm{FiO}_{2}\left(r^{2}=0.472\right)$. Significantly different LUSs were found between the non-survivor and survivor groups $(F=77.64, P<0.01)$ by repeated-measures analysis of variance. There were no significant differences between the two groups on different days. The areas under the receiver operating characteristic curves of LUS and EVLW measured by PiCCO were $0.846(P<0.01)$ and $0.918(P<0.01)$, respectively. The cut-off of LUS for prognosis prediction was 16.5 .

Conclusions: Lung ultrasonography is a non-invasive, economic, simple, user-friendly, and radiation-free bedside method for predicting the prognosis of ARDS patients. Early measurement of LUS is a better prognostic indicator in patients with ARDS.

\section{Background}

Acute respiratory distress syndrome (ARDS) is a common complication in critically ill patients. In the intensive care unit (ICU), $19 \%$ of patients with mechanical ventilation are diagnosed with ARDS, which is characterized by increased extravascular lung water (EVLW) and

\footnotetext{
* Correspondence: jiangli@sina.com

'Intensive Care Unit, Fuxing Hospital affiliated with Capital Medical University, Beijing 100038, China

Full list of author information is available at the end of the article
}

refractory hypoxemia, with mortality rates as high as 32-65 \% [1]. Diagnostic methods, such as physical examination, bedside X-ray chest film, and computed tomography (CT), provide a basic clinical evaluation of EVLW in severe cases, and they are useful for assessing lung involvement in ARDS. However, the accuracy of the former two methods is less than optimal [2]. CT scans increase safety risks because they require patient transport. Pulse index continuous cardiac output (PiCCO) technology is a highly accurate quantitative method for determination of EVLW, but it is invasive and may cause 
catheter-related infections [3]. Lung ultrasound is used to detect pulmonary edema in the early period, and 'B-lines' indicate loss of lung aeration, which may be caused by an increase in EVLW [4]. However, some researchers have introduced LUS, according to the different pulmonary ultrasonography of ARDS patients, to determine EVLW semi-quantitatively [5].

In the present study, the correlation between lung ultrasound and PiCCO monitoring was investigated to determine EVLW and evaluate the value of these two examinations in predicting ICU prognosis of ARDS patients. This economic and noninvasive bedside examination is expected to be used in the prognostic evaluation of ARDS patients.

\section{Methods}

\section{Patients}

Criteria for inclusion: (1) ARDS patients admitted to the ICU of Fu Xing Hospital affiliated with the Capital University of Medical Sciences from June 2012 to May 2013; (2) Patients meeting the diagnostic criteria of ARDS [6].

Criteria for exclusion:(1) Patients who spent $\leq 24 \mathrm{~h}$ in the ICU; (2) Patients whose mechanical ventilation time was $\leq 24 \mathrm{~h}$; (3) Patients with severe hemodynamic instability who were unable to safely change body positions; (4) Patients with severely deformed chest cage or subcutaneous emphysema who were unfit for lung ultrasound; (5) Patients who agreed to limit or withdraw life support treatment during hospitalization;(6) Patients whose family did not sign the informed consent.

\section{Data collection}

All patients were confirmed to have ARDS by chest CT on the first day of admission to the hospital. Patients were studied on the first, second, and third day after diagnosis of ARDS by lung ultrasound, bedside X-ray film, and PiCCO monitoring. Lung ultrasound was performed immediately after PiCCO monitoring.

Epidemiological data were collected, including sex, age, height, ideal weight, ARDS etiology, incidence period, and ICU outcome. The sequential organ failure assessment (SOFA) scores and lung injury score (LIS) scores of the patients were recorded every day. Parameters of mechanical ventilation were also collected every day, including tidal volume index, positive end-expiratory pressure (PEEP), static respiratory system compliance (Crs), and $\mathrm{PaO}_{2} / \mathrm{FiO}_{2}(\mathrm{P} / \mathrm{F})$.

The study was approved by the Ethics Committee of Beijing Fuxing Hospital, Capital Medical University and met all ethical requirements. All participants in both groups voluntarily joined this study and provided written informed consent.

\section{EVLW assessment}

\section{Lung ultrasound}

Lung ultrasound was performed to diagnose ARDS. A Philips C5 ultrasound system (frequency $5 \mathrm{~Hz}$; Philips Medical Systems, Suresnes, France) with an ordinary convex probe was used. Chest ultrasound was performed using the 12 regions method. All intercostal spaces of the upper and lower parts of the anterior, lateral, and posterior regions of the left and right chest walls were examined. Each region of interest was extensively examined. The worst ultrasound abnormality detected was considered to characterize the region being examined. Four ultrasound aeration patterns as shown in Fig. 1 were defined [5]: a. normal aeration $(\mathrm{N})$ : line sliding sign associated with respiratory movement or less than $3 \mathrm{~B}$ lines; b. moderate loss of lung aeration: a clear number of multiple visible B-lines with horizontal spacing between adjacent $\mathrm{B}$ lines $\leq 7 \mathrm{~mm}$ (B1 lines); c. severe loss of lung aeration: multiple $B$ lines fused together that were difficult to count with horizontal spacing between adjacent B lines $\leq 3 \mathrm{~mm}$, including'white lung' (B2 lines); and $\mathrm{d}$. pulmonary consolidation (C), hyperechoic lung tissue, accompanied by dynamic air bronchogram.

LUS was determined based on four lung ultrasonographs: $\mathrm{N}=0, \mathrm{~B} 1=1, \mathrm{~B} 2=2$, and $\mathrm{C}=3$. All patients underwent a lung ultrasound, and each of the 12 lung areas was examined. The final LUS of the patient was the sum of each regional ultrasound score (ranging from 0 to 36 ).

All lung ultrasound images were examined by two ultrasound doctors. Both doctors were blind to the clinical data of the patients and to the other doctor's ultrasound diagnosis.

\section{PiCCO monitoring}

EVLW was measured using a PiCCO system (Pulsiocath PV8115; Pulsion Medical Systems, Feldkirchen, Germany). For each patient, after $15 \mathrm{ml}$ of $0{ }^{\circ} \mathrm{C} 0.9 \%$ saline bolus was injected into the central vein, artery temperature was detected using a temperature sensor in a femoral artery catheter, and EVLW was calculated. The final EVLW was the average of three consecutive injections [7]. Extravascular lung water index (EVLWI) was the surface distribution of extra-vascular lung water in a predicted body weight $(\mathrm{PBW})$. Male: $\mathrm{PBW}(\mathrm{kg})=$ 0.91 (height $(\mathrm{cm})-152.4)+50$; female: $\mathrm{PBW}(\mathrm{kg})=0.91$ (height $(\mathrm{cm})-152.4)+45.5[8]$.

\section{Statistical analysis}

With ICU mortality as the end point, all patients were divided into a survivor group and a non-survivor group. Normally distributed continuous quantitative data were described as means \pm standard deviation (mean \pm standard deviation (SD)). Normal continuous variables were 
compared using the $t$ test, and non-normal continuous data were compared using the Mann-Whitney $U$ test. One-way analysis of variance was used to compare more than two independent variables. To access ICU outcome, a linear regression model was built that included LUS and other ARDS prognostic indices. Additionally, scatter grams (GraphPad Prism5) and receiver operating characteristic (ROC) analyses were performed.

\section{Results}

Twenty-nine ARDS patients were selected from June 2012 to March 2013. Eight of these patients matched the exclusion criteria, including three patients who died within $24 \mathrm{~h}$, two patients who were unable to complete the lung ultrasound, and three patients who signed restrictions or asked for withdrawal from life support. The clinical characteristics of 21 patients with ARDS are shown in Table 1. The average age of all patients was 78 \pm 6 years, their average height was $169 \pm 8 \mathrm{~cm}$, and their average weight was $66 \pm 7 \mathrm{~kg}$. ARDS was caused by pneumonia in 13 patients (62\%), aspiration in three patients (14\%), cardiopulmonary resuscitation in another three patients (14\%), and trauma in one patient (5\%). Fifteen patients $(72 \%)$ in the ICU were diagnosed with

Table 1 Clinical characteristics of 21 patients with acute respiratory distress syndrome

\begin{tabular}{ll}
\hline Variable & Mean \pm SD \\
\hline Age (years) & $78 \pm 6$ \\
Gender & \\
Male & $14(67 \%)$ \\
Female & $7(33 \%)$ \\
Height (cm) & $169 \pm 8$ \\
PBW (kg) & $66 \pm 7$ \\
CRX quadrants & \\
3 & $9(43 \%)$ \\
4 & $12(57 \%)$ \\
Etiology of ARDS & \\
Pneumonia & $13(62 \%)$ \\
Aspiration & $3(14 \%)$ \\
Sepsis & $3(14 \%)$ \\
CPR & $1(5 \%)$ \\
Trauma & $1(5 \%)$ \\
Onset & \\
$<48$ h & $15(72 \%)$ \\
$>48$ h & $6(28 \%)$ \\
ICU mortality & \\
Survival & $13(62 \%)$ \\
Non-survival &
\end{tabular}

$P B W$ predicted body weight, $C R X$ chest $\mathrm{X}$-ray, $C P R$ cardio pulmonary resuscitation
ARDS within $48 \mathrm{~h}$. Thirteen patients (62\%) died in the ICU.

As shown in Table 2, the LUS of ARDS patients in the non-survivor group was significantly higher than that in the survivor group $(20 \pm 5 v s .15 \pm 5, P=0.022)$. EVLWI $(16.8 \pm 4.4 \mathrm{~mL} / \mathrm{kg})$, SOFA $(15 \pm 2)$, LIS $(3 \pm 0.3)$, and Crs $(39 \pm 8)$ in the non-survivor group were significantly higher than in the survivor group on the first day, while age, height, PBW, and tidal volume were not significantly different between the two groups. Moreover, Crs and $\mathrm{P} / \mathrm{F}$ in the non-survivor group were significantly lower $\left(34 \pm 8 \mathrm{~mL} / \mathrm{cmH}_{2} \mathrm{O}, 160 \pm 42 \mathrm{mmHg}\right)$ than those in the survivor group. LUS of the non-survivor group was markedly higher than in the survivor group in the first 3 days following diagnosis of acute respiratory distress syndrome, and the other examined indicators (EVLWI, SOFA, LIS, Crs, P/F) exhibited the same tendencies with the degree of disease (Fig. 2). The average LUS and the EVLWI, SOFA, P/F, and LIS on the third day were significantly correlated $\left(r^{2}=\right.$ $0.906,0.815,0.472,0.361, P<0.01$ ) (Fig. 3).

Significant differences in LUS and EVLWI overall for 3 days were found between the non-survivor group and the survivor group $(F=11.82,22.08, P<0.01)$. The nonsurvivor group had significantly higher LUS and EVLWI values than the survivor group. The ROC curves of the average LUS and EVLWI values on the third day were valuable for evaluating clinical prognosis. There were no significant differences between the two groups in LUS or EVLWI on different days. The areas under the ROC curves of LUS and EVLW as determined by PiCCO were $0.846(P<0.01)$ and $0.918(P<0.01)$, respectively. The cutoff of LUS for prognosis prediction was 16.5 (Fig. 4).

Table 2 The characteristics of patients on day 1

\begin{tabular}{lllll}
\hline & $\begin{array}{l}\text { All } \\
(n=21)\end{array}$ & $\begin{array}{l}\text { Survivors } \\
(n=8)\end{array}$ & $\begin{array}{l}\text { Non-survivors } \\
(n=13)\end{array}$ & $p$ \\
\hline Age (years) & $78 \pm 6$ & $76 \pm 3$ & $80 \pm 2$ & 0.228 \\
Male $(\mathrm{n}(\%))$ & $14(67)$ & $5(63)$ & $9(69)$ & $<0.01$ \\
Height (cm) & $169 \pm 8$ & $170 \pm 9$ & $169 \pm 8$ & 0.866 \\
PBW (kg) & $66 \pm 7$ & $66 \pm 8$ & $65 \pm 7$ & 0.866 \\
SOFA & $13 \pm 2.6$ & $10 \pm 2$ & $15 \pm 2$ & $<0.01$ \\
PEEP (cm H$\left.H_{2} \mathrm{O}\right)$ & $10 \pm 3$ & $8 \pm 2$ & $11 \pm 3$ & 0.036 \\
CrS ( $\left.\mathrm{mL} / \mathrm{cm} \mathrm{H} \mathrm{H}_{2} \mathrm{O}\right)$ & $34 \pm 8$ & $39 \pm 8$ & $31 \pm 6$ & 0.013 \\
P/F (mmHg) & $160 \pm 42$ & $184 \pm 23$ & $145 \pm 45$ & 0.019 \\
VT (ml/kg PBW) & $6.6 \pm 0.5$ & $6.4 \pm 0.5$ & $6.7 \pm 0.5$ & 0.109 \\
LIS & $2.8 \pm 0.4$ & $2.4 \pm 0.3$ & $3 \pm 0.3$ & 0.001 \\
LUS & $18.1 \pm 5.3$ & $15 \pm 5$ & $20 \pm 5$ & 0.022 \\
EVLWI & $16.8 \pm 4.4$ & $13 \pm 3.6$ & $19 \pm 3$ & $<0.01$ \\
\hline PBW predicted body weight, SOFA sequential organ failure assessment score, \\
PEEP positive end expiratory pressure, Crs static respiratory system compliance, \\
P/F PaO2/FiO2, VT tidal volume, LIS lung injury score, LUS lung ultrasound \\
score, EVLWI extra-vascular lung water indexed to PBW
\end{tabular}



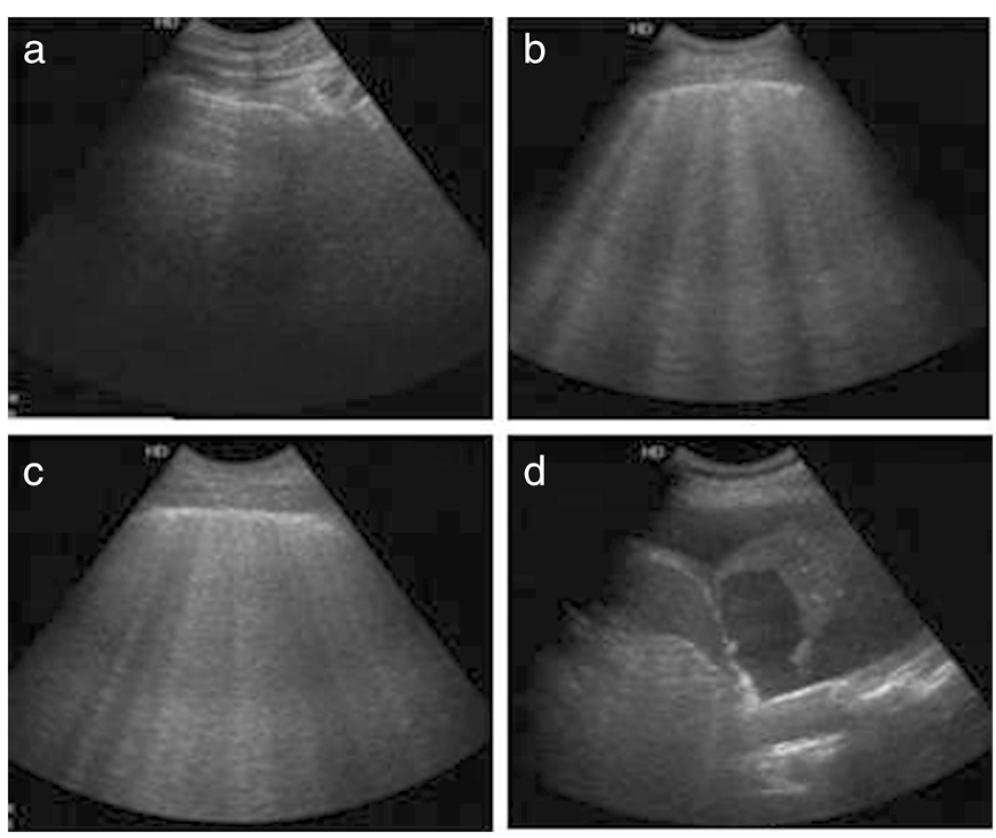

Fig. 1 Four ultrasound patterns according to lung aeration. a normal aeration $(\mathrm{N})$ : presence of lung sliding with $A$ lines or fewer than two isolated B lines; $\mathbf{b}$ moderate loss of lung aeration: multiple, well-defined B lines (B1 lines); c severe loss of lung aeration: multiple coalescent B lines (B2 lines); and $\mathbf{d}$ lung consolidation (C), the presence of a tissue pattern. For a given region of interest, points were allocated according to the worst ultrasound pattern observed: $\mathrm{N}=0, \mathrm{~B} 1$ lines $=1, \mathrm{~B} 2$ lines $=2, \mathrm{C}=3$

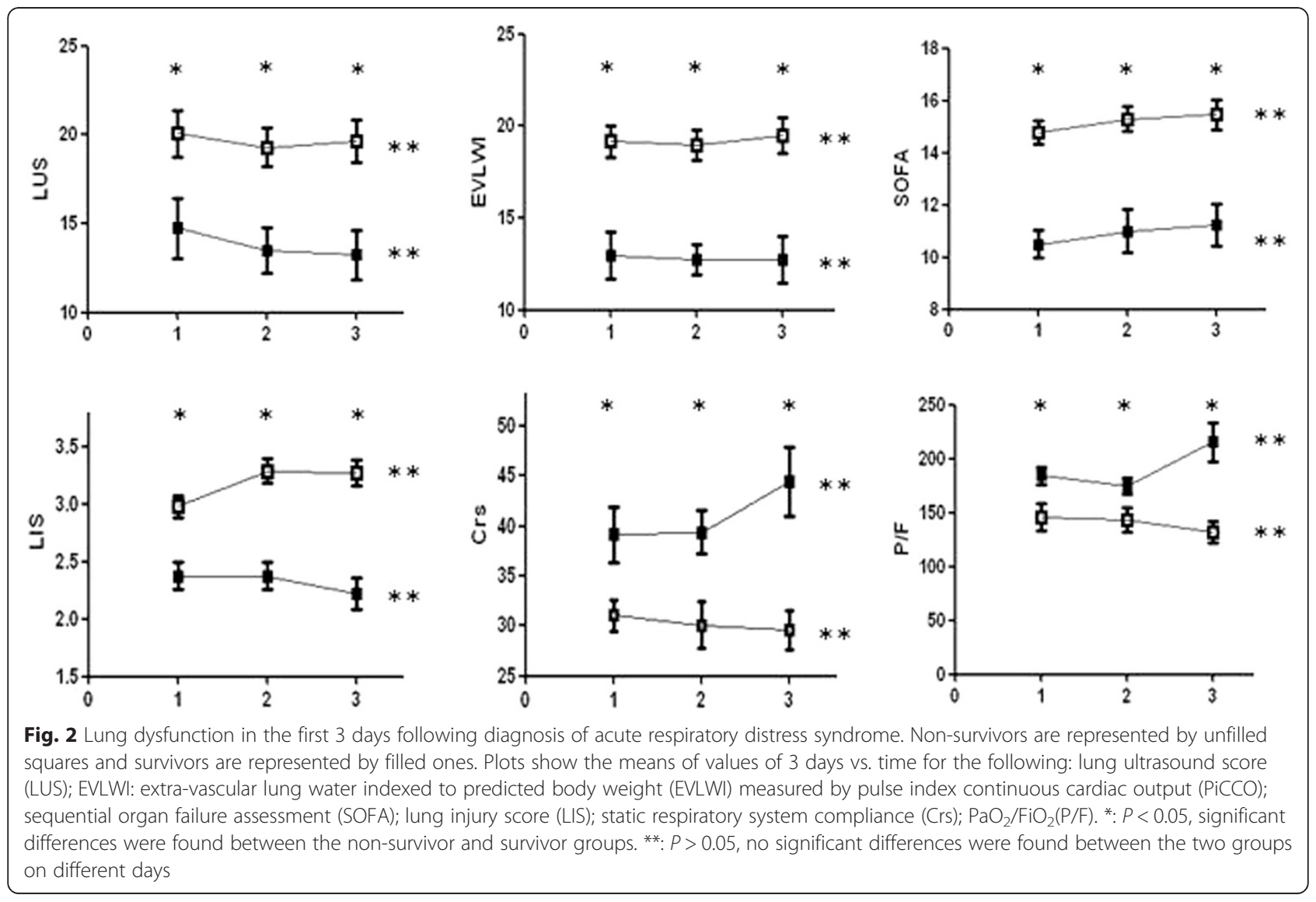



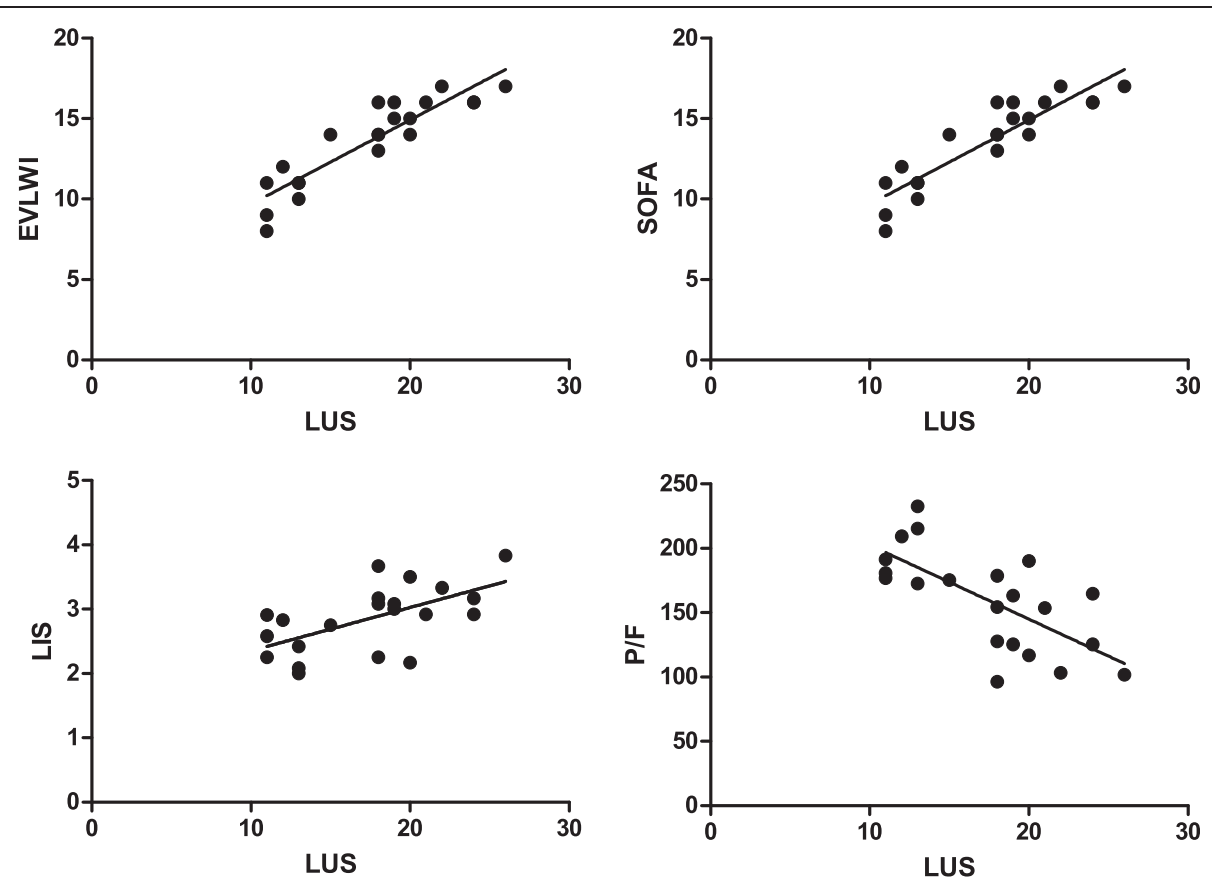

Fig. 3 Scatterplots demonstrating the correlation between lung ultrasound score (LUS) and lung dysfunction. The graphs show pooled average data for all 3 days for survivors and non-survivors. EVLWI, extravascular lung water indexed to predicted body weight; $\mathrm{P} / \mathrm{F} \mathrm{PaO} / / \mathrm{FiO}_{2} ; \mathrm{SOFA}$, sequential organ failure assessment score; LIS, lung injury score. Significant positive linear correlations were found between LUS and EVLWI, SOFA, LIS, P/F $\left(r^{2}=0.906,0.815,0.361,0.472, P<0.01\right)$

\section{Discussion}

Increased EVLW is the most important pathophysiological sign of ARDS. Additionally, the severity of pulmonary edema is closely related to the prognosis of ARDS patients. Several quantitative methods are clinically used to assess EVLW [9]. Bedside chest X-ray film is the simplest method but it is difficult to immediately detect changes in EVLW using this method. Although semi-quantitative determinations of EVLW have been made, the scores obtained were found to have a large respective divergence and to be inaccurate $[10,11]$. CT is the gold standard for assessing EVLW. Changes in CT images in regard to pleural effusion, pulmonary interstitial syndrome, and pulmonary consolidation clearly confirm the diagnosis of ARDS. Moreover, chest CT software has been developed to accurately measure EVLW. However, to perform a CT scan, the patient has to be moved to the CT room. This movement is particularly dangerous, especially for patients with severe unstable hemodynamics, and it may even threaten the patient's life [12, 13]. Recently, PiCCO technology has become widely used in clinics [14]. Kuzkovet al. found a positive linear correlation between EVLW and acute lung injury severity index (Crs, P/F, and LIS), and this
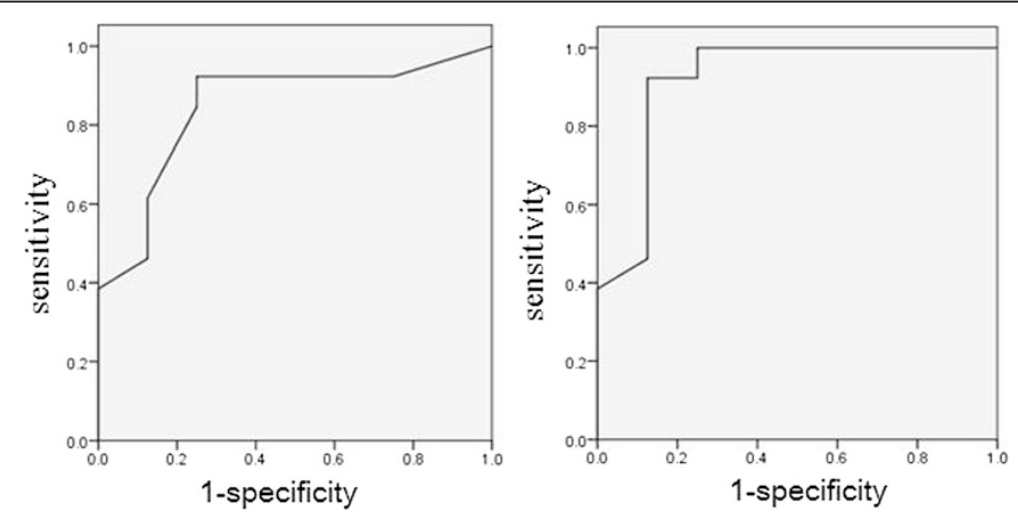

Fig. 4 Receiver operating characteristic curves of lung ultrasound score (LUS) and extra-vascular lung water (EVLW) for mortality. The area under the curve (95\% confidence interval [CI]) was $0.846 \pm 0.91$ and $0.918 \pm 0.72$ for LUS and EVLW, respectively 
correlation can help doctors to effectively characterize the clinical prognosis of patients [15]. PiCCO technology can provide a quantitative determination of EVLW, and EVLWI has emerged as a widely used method to evaluate the severity of pulmonary edema. However, PiCCO technology is expensive, and the procedure is invasive, therefore it puts patients at risk of infection because of the use of a catheter, and this limits its clinical application.

Lung ultrasonography has been widely used to assess EVLW clinically in recent years. Jambrik et al. determined the relationship between lung ultrasound and chest X-ray using PiCCO technology to assess EVLW [16]. To date, lung ultrasound has been applied in differential diagnosis of the acute respiratory failure etiology [17], in the EVLW assessment of hemodialysis (HD) patients $[18,19]$, even more in the extravascular lung water assessment of heart failure patients [20,21], concluding that lung ultrasound is a relatively new method which has gained a growing acceptance as a bedside diagnostic tool to assess pulmonary interstitial fluid and alveolar oedema [22]. Also, lung ultrasound has been applied in the selection of the best PEEP of ARDS patients [23]. PEEP $>5 \mathrm{cmH}_{2} \mathrm{O}$ might aid in the prevention of alveolar collapse, improve the oxygenation state, and reduce ventilator-induced lung injury [24]. The strategy of low tidal volume and high PEEP ventilation could significantly reduce 28-day mortality in ARDS patients [25], increase the number of days of weaning success, and reduce the incidence of organ failure [26, 27]. However, the strategies of high PEEP ventilation and low PEEP ventilation did not show significant differences in regard to the prognosis of ARDS patients [28-30]. A metaanalysis showed that a high PEEP level could reduce the mortality of patients with moderate or severe ARDS (P/ $\mathrm{F} \leq 200 \mathrm{mmHg}$ ) but had no effect on the mortality of patients with mild ARDS [31].

Lung ultrasonography is rarely used in prognostic evaluation of ARDS patients. Frassi et al. divided patients with chest pain and dyspnea into mild, moderate, and severe groups based on the number of lung ultrasound comet tails (ULCs) and found a direct correlation between the number of ULCs and mortality rate [32]. Acute Physiology and Chronic Health Evaluation II and SOFA scores are good predictors of death risk in ARDS patients, while LIS and $\mathrm{P} / \mathrm{F}$ have lower prognostic abilities [33-35]. Recently, EVLWI measured using PiCCO technology is being used with increasing frequency to assess ARDS prognosis. EVLWI is directly correlated with LIS, Crs, and, obviously, P/F [36-38]. Additionally, EVLWI of pediatric patients with acute respiratory distress could predict survival prognosis and mechanical ventilation duration [39]. A metaanalysis covering 670 patients in 11 studies of 9 countries showed that EVLWI was a better predictor of the mortality of severe patients [40].
In this study, LUS was closely related to several ARDS prognostic indices (EVLWI, LIS, Crs, and P/F) and was able to predict death risk and served as a diagnostic marker of ARDS. Early measurement of LUS is a better diagnostic indicator of acute lung injury than late measurement. Compared with other examinations, lung ultrasound is a non-invasive, economic, repeatable, simple, user-friendly, radiation-free bedside method for the prognosis of ARDS patients and for determination of the best treatment plan.

\section{Conclusions}

In summary, significant positive correlations were found between LUS and EVLWI measured by PiCCO. Both were effective clinical examination tools for the evaluation of ICU outcome in ARDS patients. Lung ultrasound diagnosis is simple, quick, non-invasive, economic, and rather accurate and is recommended for clinical use.

\section{Abbreviations}

ARDS: Acute respiratory distress syndrome; PiCCO: Pulse index continuous cardiac output; LUS: Lung ultrasound score; PBW: Predicted body weight; EVLW: Extra-vascular lung water; EVLWI: Extra-vascular lung water indexed to PBW; SOFA: Sequential organ failure assessment score; LIS: Lung injury score; $\mathrm{P} / \mathrm{F}: \mathrm{PaO}_{2} / \mathrm{FiO}_{2} ; \mathrm{ICU}$ : Intensive care unit; PEEP: Positive end expiratory pressure; Crs: Static respiratory system compliance.

\section{Competing interests}

The authors declare that they have no competing interests.

\section{Authors' contributions}

$\mathrm{L}$ and $\mathrm{ZZ}$ conceived and planned the program. XMX participated in the design of the study and performed the statistical analysis. ZZ drafted the manuscript and revised it critically for important intellectual content. BZ and QJ recorded the patients' information. ZZ and MPW collected, analyzed, and interpreted the data. JX and DZ helped with lung ultrasound training. All authors read and approved the final manuscript.

\section{Acknowledgments}

The authors sincerely thank Dr. Bin Du (Division of Intensive Care Unit, Peking Union Medical College Hospital, China) for kindly contributing suggestions for the conception and design of this study. The authors also sincerely thank Dr. Xiaoxia Peng (School of Public Health, Capital Medical University, China) for her advice on the statistical analysis of the data. The study was undertaken with funding support from Beijing Municipal Science \& Technology Commission No.Z121107001012125.

\section{Author details}

${ }^{1}$ Intensive Care Unit, Fuxing Hospital affiliated with Capital Medical University, Beijing 100038, China. ${ }^{2}$ Department of Ultrasonography, Fuxing Hospital affiliated with Capital Medical University, Beijing 100038, China.

Received: 13 December 2014 Accepted: 4 August 2015

Published online: 23 August 2015

\section{References}

1. Irish Critical Care Trials Group. Acute lung injury and the acute respiratory distress syndrome in Ireland: a prospective audit of epidemiology and management. Critical Care. 2008;12:R30.

2. Rubenfeld G, Caldwell E, Granton J, Hudson LD, Matthay MA. Interobserver variability in applying a radiographic definition for ARDS. Chest. 1999;116:1347-53.

3. Rossi P, Rudehill A, Konrad D, Weitzberq E, Oldner A. Comparison of a single indicator and gravimetric technique for estimation of extravascular lung water in endotoxemic pigs. Crit Care Med. 2006;34:1437-43.

4. Volpicelli G. Lung sonography. J Ultrasound Med. 2013;32:165-17. 
5. Volpicelli G, Skurzak S, Boero E, Carpinteri G, Tenqattini M, Stefanone V, et al. Lung ultrasound predicts well extravascular lung water but is of limited usefulness in the prediction of wedge pressure. Anesthesiology. 2014;121:320-7.

6. ARDS Definition Task Force, Rubenfeld GD, Thompson BT, Ferquson ND, Galdwell E, Fan E, et al. Acute respiratory distress syndrome: the Berlin Definition. JAMA. 2012;307.

7. Katzenelson R, Perel A, Berkenstadt H, Preiman S, Kogan S, Sternik L, et al. Accuracy of transpulmonary thermodilution versus gravimetric measurement of extravascular lung water. Crit Care Med. 2004;32:1550-4.

8. Devine B. Gentamicin therapy. Drug Intell Clin Pharm. 1974;8:650-5.

9. Halperin BD, Feeley TW, Mihm FG, Chiles C, Guthaner DF, Blank NE. Evaluation of the portable chest roentgenogram for quantitating extravascular lung water in critically ill adults. Chest. 1985;88:649-52.

10. Giuntini C, Pistoles M, Miniati M, Fazio F. Theoretical and practical considerations of measuring extravascular lung water. J Thorac Imaging. 1988:3:36-43.

11. Pistolesi M, Giuntini C. Assessment of extravascular lung water. Radiol Clin North Am. 1978;16:551-74

12. Malbouisson LM, Preteux F, Puybasset L, Grenier P, Coriat P, Rouby JJ. Validation of a software designed for computed tomographic (CT) measurement of lung water. Intensive Care Med. 2001;27:602-8.

13. Rouby JJ, Puybasset L, Nieszkowska A, Lu Q. Acute respiratory distress syndrome: lessons from computed tomography of the whole lung. Crit Care Med. 2003;31:S285-295.

14. Effros RM, Pornsuriyasak P, Porszasz J, Casaburi R. Indicator dilution measurements of extravascular lung water: basic assumptions and observations. Am J Physiol Lung Cell Mol Physiol. 2008;294:L1023-1031.

15. Kuzkov W, Kirov MY, Sovershaev MA, Kuklin VN, Suborov EV, Waerhauq K, et al. Extravascular lung water determined with single transpulmonary thermodilution correlates with the severity of sepsis-induced acute lung injury. Crit Care Med. 2006;34:1647-53.

16. Jambrik Z, Monti S, Coppola V, Aqricola E, Mottola G, Miniati M. Usefulness of ultrasound lung comets as a nonradiologic sign of extravascular lung water. Am J cardiol. 2004;93:1265-70.

17. Lichtenstein DA, Meziere GA. Relevance of lung ultrasound in the diagnosis of acute respiratory failure: the BLUE protocol. Chest. 2008;134:117-25.

18. Noble VE, Murray AF, Capp R, Syivia-reardon MH, Steele DJ, Liteplo A. Ultrasound assessment for extravascular lung water in patients undergoing hemodialysis. Time course for resolution. Chest. 2009;135:1433-9.

19. Mallamaci F, Benedetto FA, Tripepi R, Rastelli S, Castellino P, Tripepi G, et al. Detection of pulmonary congestion by chest ultrasound in dialysis patients. JACC Cardiovasc Imaging. 2010;3:586-94.

20. Agricola E, Bove T, Oppizzi M, Marino G, Zanqriuo A, Marqonato A, et al. "Ultrasound comet-tail images": a marker of pulmonary edema: a comparative study with wedge pressure and extravascular lung water. Chest. 2005:127:1690-5.

21. Agricola E, Picano E, Oppizzi M, Pisani M, Meris A, Fraqasso G, et al. Assessment of stress-induced pulmonary interstitial edema by chest ultrasound during exercise echocardiography and its correlation with left ventricular function. J Am Soc Echocardiogr. 2006;19:457-63.

22. Volpicelli G, Melniker LA, Cardinale L, Lamorte A, Frascisco MF. Lung ultrasound in diagnosing and monitoring pulmonary interstitial fluid. Radiol Med. 2013;118:196-205.

23. Bouhemad B, Brisson H, Le-Guen M, Arbelot C, Lu Q, Rouby JJ. Bedside ultrasound assessment of positive end-expiratory pressure-induced lung recruitment. Am J Respir Crit Care Med. 2011;183:341-7.

24. Gattinoni L, Caironi P, Cressoni M, Chiumello D, Ranieri VM, Quintel M, et al. Lung recruitment in patients with the acute respiratory distress syndrome. N Engl J Med. 2006;354:1775-86.

25. The Acute Respiratory Distress Syndrome Network. Ventilation with lower tidal volumes as compared with traditional tidal volumes for acute lung injury and the acute respiratory distress syndrome. N Engl J Med. 2000;342:1301-8

26. Amato MB, Barbas CS, Medeiros DM, Maqaldi RB, Schetlino GP, Lorenzi-Filho $\mathrm{G}$, et al. Effect of a protective-ventilation strategy on mortality in the acute respiratory distress syndrome. N Engl J Med. 1998;338:347-54.

27. Villar J, Kacmarek RM, Perez-Mendez L, Aguirre-Jaime AA. A high positive end-expiratory pressure, low tidal volume ventilatory strategy improves outcome in persistent acute respiratory distress syndrome: a randomized, controlled trial. Crit Care Med. 2006;34:1311-8.
28. Mercat A, Richard JC, Vielle B, Jaber S, Osman D, Diehl JL, et al. Positive endexpiratory pressure setting in adults with acute lung injury and acute respiratory distress syndrome: a randomized controlled trial. JAMA. 2008:299:646-55.

29. Meade MO, Cook DJ, Guyatt GH, Slutsky AS, Arabi YM, Cooper DJ, et al. Ventilation strategy using low tidal volumes, recruitment maneuvers, and high positive end-expiratory pressure for acute lung injury and acute respiratory distress syndrome: a randomized controlled trial. JAMA. 2008;299:637-45

30. Brower RG, Lanken PN, Maclntyre N, Matthay MA, Morris A, Ancukiewicz M, et al. Higher versus lower positive end-expiratory pressures in patients with the acute respiratory distress syndrome. N Engl J Med. 2004;351:327-36.

31. Briel M, Meade M, Mercat A, Brower RG, Talmor D, Walter SD, et al. Higher vs lower positive end-expiratory pressure in patients with acute lung injury and acute respiratory distress syndrome: systematic review and metaanalysis. JAMA. 2010;303:865-73.

32. Frassi F, Garqani L, Tesorio P, Raciti M, Mottola G, Picano E. Prognostic value of extravascular lung water assessed with ultrasound lung comets by chest sonography in patients with dyspnea and/or chest pain. J Card Fail. 2007;13:830-5.

33. Luecke T, Muench E, Roth H, Friess U, Paul T, Kleinhuber K, et al. Predictors of mortality in ARDS patients referred to a tertiary care centre: a pilot study. Eur J Anaesthesiol. 2006;23:403-10.

34. Agarwal R, Aggarwal AN, Gupta D, Behera D, Jindal SK. Etiology and outcomes of pulmonary and extrapulmonary acute lung injury/ARDS in a respiratory ICU in North India. Chest. 2006;130:724-9.

35. Monchi M, Bellenfant F, Cariou A, Joly LM, Thebert D, Laurent I, et al. Early predictive factors of survival in the acute respiratory distress syndrome. A multivariate analysis. Am J Respir Crit Care Med. 1998;158:1076-81.

36. Berkowitz DM, Danai PA, Eaton S, Moss M, Martin GS. Accurate characterization of extravascular lung water in acute respiratory distress syndrome. Crit Care Med. 2008;36:1803-9.

37. Phillips CR, Chesnutt MS, Smith SM. Extravascular lung water in sepsisassociated acute respiratory distress syndrome: indexing with predicted body weight improves correlation with severity of illness and survival. Crit Care Med. 2008;36:69-73.

38. Craig TR, Duffy MJ, Shyamsundar M, McDowell C, McLaughlin B, Elborn JS, et al. Extravascular lung water indexed to predicted body weight is a nove predictor of intensive care unit mortality in patients with acute lung injury. Crit Care Med. 2010;38:114-20.

39. Lubrano R, Cecchetti C, Elli M, Tomasello C, Guido G, Di Nardo M, et al. Prognostic value of extravascular lung water index in critically ill children with acute respiratory failure. Intensive Care Med. 2011;37:124-31.

40. Zhang Z, Lu B, Ni H. Prognostic value of extravascular lung water index in critically ill patients: a systematic review of the literature. J Crit Care. 2012;27:420.e1-8.

\section{Submit your next manuscript to BioMed Central and take full advantage of:}

- Convenient online submission

- Thorough peer review

- No space constraints or color figure charges

- Immediate publication on acceptance

- Inclusion in PubMed, CAS, Scopus and Google Scholar

- Research which is freely available for redistribution 